\title{
Does gender matter? The association between different digital media activities and adolescent well-being
}

\author{
Robert Svensson ${ }^{1 *}$, Björn Johnson ${ }^{2}$ and Andreas Olsson ${ }^{3}$
}

\begin{abstract}
Background: Previous research on the relationship between social media use and well-being in adolescents has yielded inconsistent results. We addressed this issue by examining the association between various digital media activities, including a new and differentiated measure of social media use, and well-being (internalizing symptoms) in adolescent boys and girls.

Method: The sample was drawn from the four cross-sectional surveys from the Öckerö project (2016-2019) in eight municipalities in southern Sweden, consisting of 3957 adolescents in year 7 of compulsory education, aged 12-13. We measured the following digital media activities: playing games and three different activities of social media use (chatting, online sociability, and self-presentation). Our outcome measure was internalizing symptoms. Hypotheses were tested with linear regression analysis.
\end{abstract}

Results: Social media use and playing games were positively associated with internalizing symptoms. The effect of social media use was conditional on gender, indicating that social media use was only associated with internalizing symptoms for girls. Of the social media activities, only chatting and self-presentation (posting information about themselves) were positively associated with internalizing symptoms. Self-presentation was associated with internalizing symptoms only for girls.

Conclusion: Our study shows the importance of research going beyond studying the time spent on social media to examine how different kinds of social media activities are associated with well-being. Consistent with research in psychology, our results suggest that young girls posting information about themselves (i.e. self-presentation) might be especially vulnerable to display internalizing symptoms.

Keywords: Adolescents, Screen time, Social media, Playing games, Well-being

\section{Introduction}

Adolescents of today spend an increasing portion of their free time using different digital media, such as smartphones, computers, and tablets [1]. In Sweden, the proportion of 14-year old adolescents using the internet for more than $3 \mathrm{~h}$ /day increased from $30 \%$ in 2010 to $76 \%$ in

\footnotetext{
*Correspondence: robert.svensson@mau.se

1 Department of Criminology, Malmö University, 20506 Malmö, Sweden

Full list of author information is available at the end of the article
}

2020 [2], and in the US, 45\% of teens report that they are online on a "near-constant" basis [3]. At the same time, the rate of depression, anxiety, and suicide among adolescents has risen to historically high levels over the past 10-15 years [4-6]. For example, the level of depression in 10-17-old Swedish girls has surged from approximately 500 to more than 1.000 per 100.000 from 2008 to 2018 [7]. Although the reasons for this increase in depression rate are likely to be multifaceted, including changed 
diagnostic criteria, the use of digital media has attracted increasing attention as a potential causal factor [8].

The association between digital media use (e.g., playing games, social media use, watching TV) or social media use more specifically (e.g., different activities on Instagram, Facebook or Snapchat) and well-being has been examined (and debated) $[9,10]$ in several studies with mixed results [11-13]. Whereas the majority of studies - many of which have been based on crosssectional designs - have found a negative association [8, 11], the few available longitudinal studies have shown either that social media use predicts lower well-being in terms of depression and internalizing symptoms (e.g., depression, anxiety, hypersensitivity, headache, worry) [14-17], no association [18-20], or that depression predicts an increase in social media use [21, 22]. In addition, some investigators have found evidence of a curvilinear u-shaped association [23, 24]. Other research has examined potential mediators, and found that the association between social media use and well-being could be mediated by factors, such as cyberbullying, lack of sleep, and lower physical activity [15].

An intriguing possibility is that the inconsistent results in the existing literature are related to key methodological differences between studies, limiting the generalizability and conclusions that can be drawn from them [1]. To move beyond these limitations, we performed a large cross-sectional study and used in-depth measures of social media activities and internalizing symptoms, which constitute an important aspect of mental wellbeing. Our goal was to provide a deeper understanding of, not only where on the internet adolescents spend their time, but what kind of activities might contribute to changes in mental well-being. To clarify the specific contributions of our study, we begin by listing three central limitations in existing research.

A first limitation in past research that might contribute to the mixed findings is the lack of interest in specific digital media activities, and to what degree they are differently associated with well-being [18, 25, 26]. For example, studies that do not differentiate clearly between various digital media activities, have found both negative [27], and non-existent associations with well-being [18]. Internet use can include a wide range of activities that differ across gender in terms of agency, display mode, and social meaning. Therefore, it is important to examine different activities separately. A number of studies have found that playing games is associated with lower well-being in terms of internalizing problems and depressive symptoms [28-31]. Importantly, social media use was found to be more strongly associated with wellbeing than playing games $[1,14]$. One explanation of this difference could be that social media presents more opportunities for social comparison, which is known to decrease well-being, in comparison to gaming [1].

A second limitation in past research that might contribute to the mixed findings, is the varying measures used to assess social media use more specifically. For example, adolescents have been asked to define social media themselves [32], and self-report how active they have been on different platforms [20,33], whether they chat or interact with their friends on different platforms $[17,34]$, and use a combined measure of instant messaging, photo-sharing or other social media activities on different platforms [22]. Different means of assessing social media might tap into distinct activities with varying relevance for the development and expression of wellbeing. We argue that it is important to go beyond existing approaches to examine both how and in what way different social media activities are associated with well-being in boys and girls separately.

To address these open questions, our study focuses on three different social media activities: (i) chatting in realtime with friends on platforms that are "private" (oneon one or private group chats); (ii) online sociability, i.e. communication taking place in public social media that can be viewed by others (not necessarily in real time); and (iii) self-presentation, such as selfies, film clips or other types of personal information that can be viewed by others. As far as we know, no previous study has examined how these three activities are associated with well-being for boys and girls. Self-presentation, which has been highlighted as a key factor underlying the association between social media use and adolescent well-being [3538], indicates an individual's motivation to "brand" themselves and to reach digital social status through likes and new followers [39]. This search for social rewards lays the ground for social comparisons, known to affect wellbeing negatively $[35,40]$. Indeed, recent meta-analyses $[41,42]$ demonstrate that social comparison in general, and upwards social comparison (i.e. comparison with superior other) in particular, predicts a decrease in wellbeing $[35,39,43]$. The lack of positive feedback (i.e. social rewards) and the presence of social punishment from the social media community has been shown to have a negative influence on the adolescent's well-being $[13,44]$. In light of these lines of research, we assume that a higher reliance on self-presentation renders the individual more vulnerable to negative feedback.

A third limitation in previous research is that previous studies have treated gender as a control variable, overlooking the possibility that the association between digital media use and well-being is different for boys and girls $[14,26]$. For example, some researchers have analysed boys and girls together, founding that digital media use was not associated with well-being [20], whereas others 
have shown girls to have lower well-being as indicated by, for example, depressive symptoms $[6,37,45]$, anxiety $[6,45]$ and internalizing problems [16]. Girls use social media $[1,2,28,46]$ and chat with friends [28] more than boys who in turn tend to spend more time gaming $[1,2$, 28]. In addition, girls more frequently post different types of selfies, use filters, manipulate their photos, and delete post more frequently than boys, whereas boys update their profile more often on sport and technology $[2,37$, $43,47,48]$. Against this background we argue that it is important to examine the associations by gender.

The importance of including gender as a variable is supported by previous research finding social media use to be more strongly associated with well-being for girls than for boys $[1,17,49,50]$, whereas some did not find any gender differences [16]. Differences in the selfie culture may be one explanation that helps us to understand why the association between self-presentation and depressive symptoms is larger for girls [37]. Gaming has been found to be associated with well-being for both boys and girls [1]. These gender differences indicate that social media use, and different activities of social media may have a larger association with well-being for girls, and that the association between gaming and well-being might be rather similar for boys and girls.

To sum up, we identified three areas of limitations in previous research related to the importance of separately examining the role of (1) kinds of digital media activities, (2) different types of activities within social media use, and (3) gender. In our cross-sectional study, we aim to use various measures of digital media activities, well-developed assessments of social media activities, and examine how these activities are associated with internalizing symptoms as a measure of girls' and boys' well-being. In spite of the inherent limitations of crosssectional designs, which are unsuitable to make strong causal claims, we believe that these methodological improvements will contribute to our understanding of the specific processes linking social media use and mental health problems and well-being in adolescents.

We test the following three hypotheses:

H1: Different digital media activities are differently associated with internalizing symptoms: (a) social media use will be positively associated with internalizing symptoms, and (b) playing games will be positively associated with internalizing symptoms, but the association will be stronger for social media use compared to playing games.

H2: Different social media activities, such as (a) chatting, (b) online sociability and (c) self-presentation, will all be positively associated with internalizing symptoms.
H3: Social media use and different activities of social media use, such as (a) chatting, (b) online sociability and (c) self-presentation will be more strongly associated with internalizing symptoms for girls than for boys. The association between playing games and internalizing symptoms will not differ between girls and boys.

\section{Method \\ Study design}

The data used are based on secondary data analysis from four cross-sectional surveys from the Öckerö project [51, 52], an evaluation of an alcohol prevention program [53]. The project included an annual self-report survey conducted in 17 secondary schools in eight small municipalities in the county of Skåne, Sweden. The survey was conducted in all classes in years 7-9 (i.e. 12-15 years of age), the final 3 years of compulsory education. The survey was conducted at the beginning of the autumn term in each of four successive years, 2016-2019.

\section{Participants}

In this study, we employ data on youths in year seven (on average 13years of age) year 2016, 2017, 2018 and 2019 from the Öckerö project. The study constitutes a census of 4256 adolescents. Following listwise deletion of missing values, the analyses below are based on 3957 respondents (50.2\% boys). The non-responses were fairly evenly distributed across the included variables.

\section{Data collection}

The data were collected through an online questionnaire that was introduced to the class members by researchers and assistants working on the project. The questionnaire was completed during lesson time and took an average of $30 \mathrm{~min}$. Before completing the questionnaires, the students were given detailed information about the purpose of the survey. They were also informed that their participation was voluntary and anonymous. The research design and study procedures were approved by The Regional Ethical Review Board in Lund.

\section{Measures \\ Dependent variable}

Internalizing symptoms scale was based on an additive index consisting of six statements: (1) I often feel sad and depressed, (2) I often worry about the future, (3) I often feel anxious and worried, (4) I often have a stomach ache or headache, (5) I often feel lonely, (6) I have difficulty sleeping and eating (response alternatives: totally disagree / disagree / agree / totally agree). The items used in this scale have carefully been chosen 
and measure emotional responses to stressors that are inwardly directed [54] and are similar to the emotional symptom dimension of the SDQ scale [55]. The scale has an alpha value of .87. This scale has previously been used in the study of alcohol use [51]. Similar measures have been used in previous research [16]. High scores indicate that the respondents have high level of internalizing symptoms.

\section{Independent variables}

Social media use is an additive index based on three items. How often do you use a computer, mobile phone or tablet to do one of the following activities? (1) Talk to friends at Skype, Kik, Viber, Whats's app or similar referred to as Chatting, (2) Stay in contact with and stay informed about my friends via Facebook, Instagram or similar - referred to as Online sociability, (3) Post information about myself on Facebook, Instagram, Snapchat or other social media - referred to as Self-presentation. Response alternatives: never / about once a month / about once a week and / several times a week / every day. The three measures of social media use will also be analysed as separate measures of social media in a supplemental regression model. Although, chatting and online sociability seems to be rather similar, we argue that it will not be a problem of using them as distinct components $(r=.36)$. The measures will be treated as continuous variables in the following analyses.

Playing games is a single item based on How often do you use a computer, mobile phone or tablet to do one of the following activities? (1) Play games. Response alternatives: never / about once a month / about once a week and / several times a week / every day. The measure will be treated as a continuous variable in the following analyses. These items of digital activities have been used in previous studies [52].

Demographic variables are represented using two different measures in the analyses. Gender is coded as 0 for girls and 1 for boys. Country of birth is coded as 0 if the respondent is born abroad and 1 if the respondents is born in Sweden. Sweden is a country with a high proportion immigrant from non-European countries and therefore we decided to adjust for country of birth.

Year represents the year when the study was conducted and is used as three dummy variables. Year 2016 is the reference category in the analyses and year 2017, 2018 and 2019 are the other years involved in the analyses.

For a description of the measures used see Table 1.

\section{Statistical analyses}

First, we compared the mean values of internalizing symptoms, social media use, and the three dimensions of social media use, and playing games by gender. We also
Table 1 Descriptive statistics ( $N=3957)$

\begin{tabular}{lllll}
\hline & Mean/\% & SD & Min & Max \\
\hline Internalizing symptoms & 10.51 & 4.33 & 5 & 24 \\
Social media use & 10.14 & 3.07 & 3 & 15 \\
$\quad$ Chatting & 3.78 & 1.39 & 1 & 5 \\
$\quad$ Online sociability & 3.83 & 1.35 & 1 & 5 \\
$\quad$ Self-presentation & 2.54 & 1.36 & 1 & 5 \\
Playing games & 3.57 & 1.30 & 1 & 5 \\
Boys & $50.2 \%$ & - & 0 & 1 \\
Born in Sweden & $86.8 \%$ & - & 0 & 1 \\
Year 2016 & $25.2 \%$ & - & 0 & 1 \\
Year 2017 & $24.1 \%$ & - & 0 & 1 \\
Year 2018 & $24.8 \%$ & - & 0 & 1 \\
Year 2019 & $25.9 \%$ & - & 0 & 1 \\
\hline
\end{tabular}

calculated the effect size measure of Cohen's $d$. Second, we estimated a number of ordinary least squares regression models. In the first model, we included social media use, playing games and gender. As curvilinearity could be a problem in interaction models $[56,57]$ and since previous research have found evidence of curvilinear associations $[9,23]$, we also test for curvilinear relationships and added squared terms of social media use and playing games to the linear model. In the second model, we included several interaction terms of gender $\times$ social media use and gender $\times$ playing games. In this model we also added our squared terms of social media use and playing games. In all the regression models we adjust for country of birth, year of study, the interaction between gender $\times$ year and dummies of the 17 schools. Finally, all the regression models were also estimated using the three different dimensions of social media use, i.e. chatting, online sociability and self-presentation. In these models we also test for curvilinear relationships by adding squared terms. The continuous variables were mean-centered prior to their inclusion in interaction terms. Finally, to illustrate the interactions, we plotted the interaction using the predictive margins plot command in Stata. All analyses were conducted in Stata/SE version 13.1.

\section{Results}

Table 2 presents differences between girls and boys in relation with internalizing symptoms, social media use, chatting, online sociability, self-presentation and playing games. We observe that girls report significantly higher on the internalizing symptoms than boys $(t=19.99, p=<$ .001). Moreover, girls score significantly higher on the measure of social media use $(t=11.47, p=<.001)$, as well as on chatting $(t=5.14, p=<.001)$, online sociability $(t=9.49, p=<.001)$ and self-presentation $(t=11.01$, 
Table 2 Internalizing symptoms and digital activities by gender, independent $t$-test and effect sizes (Cohen's $d)(N=3957)$

\begin{tabular}{|c|c|c|c|c|c|c|c|}
\hline & \multicolumn{2}{|l|}{ Girls } & \multicolumn{2}{|l|}{ Boys } & \multirow[b]{2}{*}{$t$-test } & \multirow[b]{2}{*}{$p$-value } & \multirow[b]{2}{*}{$d$} \\
\hline & Mean & SD & Mean & SD & & & \\
\hline Internalizing symptoms & 11.83 & 4.58 & 9.20 & 3.63 & 19.99 & $<.001$ & .64 \\
\hline Social media use & 10.70 & 2.90 & 9.60 & 3.13 & 11.47 & $<.001$ & .36 \\
\hline Chatting & 3.90 & 1.35 & 3.67 & 1.43 & 5.14 & $<.001$ & .16 \\
\hline Online sociability & 4.03 & 1.28 & 3.63 & 1.39 & 9.49 & $<.001$ & .30 \\
\hline Self-presentation & 2.77 & 1.37 & 2.30 & 1.32 & 11.01 & $<.001$ & .35 \\
\hline Playing games & 3.03 & 1.29 & 4.11 & 1.07 & -28.81 & $<.001$ & -.92 \\
\hline
\end{tabular}

$p=<.001)$. Boys report significantly higher on the playing game measure $(t=-28.81, p=<.001)$. The effect sizes presented by the Cohen's $d$ range from .16 (for online sociability) to -.92 (for playing games).

In order to examine our key hypotheses, i.e. whether the different digital media activities are differently associated with internalizing symptoms for girls and boys we present a number of regression models in Table 3 . The results presented in model 1 show that social media use and playing games are both positively associated with internalizing symptoms. According to the standardized regression coefficient, social media use is slightly more strongly associated with internalizing symptoms than playing games. The results also show that the squared terms of the two measures are significant, indicating a curvilinear association between both digital media activities and internalizing symptoms. Gender is negatively associated with internalizing symptoms, which means that girls report higher on internalizing symptoms, adjusting for the other predictors.

In the second model, where the interaction terms included, and the results show that the interaction between gender and social media use is strongly negatively associated with internalizing symptoms $(B=-.191$, $p=<.001)$, meaning that the association between social media use is more pronounced for girls then for boys. The squared term of social media use is still associated with internalizing symptoms, indicating that the association is not linear it is curvilinear. Finally, the interaction between gender and playing games is not significantly associated with internalizing symptoms, i.e. there is no gender differences in the association between playing games in relation with internalizing symptoms.

To visualize the interaction, we plotted the predicted values of internalizing symptoms on social media use by gender, with their 95\% CIs. Figure 1 show that the association between social media use and internalizing symptoms is only significant for girls but not for boys. The association is curvilinear indicating that the association between social media use and internalizing symptoms becomes more and more pronounced the more girls are using the social media.

Finally, we estimated the regression models using the three different dimensions of social media use - chatting,

Table 3 The relationship between internalizing symptoms and digital activities (social media use and playing games). Ordinary least square regression

\begin{tabular}{|c|c|c|c|c|c|c|}
\hline & \multicolumn{2}{|l|}{ Model 1} & \multirow[b]{2}{*}{$p$-value } & \multicolumn{2}{|c|}{ Model 2} & \multirow[b]{2}{*}{$p$-value } \\
\hline & $B$ & Beta & & $B$ & Beta & \\
\hline Social media use & .191 & .135 & $<.001$ & .288 & .204 & $<.001$ \\
\hline Social media use ${ }^{2}$ & .032 & .088 & $<.001$ & .027 & .075 & $<.001$ \\
\hline Playing games & .320 & .096 & $<.001$ & .294 & .088 & .002 \\
\hline Playing games ${ }^{2}$ & .143 & .060 & .001 & .139 & .058 & .003 \\
\hline Boy & -2.389 & -.278 & $<.001$ & -2.343 & -.270 & $<.001$ \\
\hline Social media use $\times$ Boy & & & & -.191 & -.098 & $<.001$ \\
\hline Playing games $\times$ Boy & & & & .072 & .013 & .521 \\
\hline Controls $^{a}$ & Yes & & & Yes & & \\
\hline$R^{2}$ & .129 & & & .133 & & \\
\hline $\mathrm{N}$ & 3957 & & & 3957 & & \\
\hline
\end{tabular}

Note: $B=$ unstandardized coefficient; Beta $=$ standardized coefficient. The $p$-values are calculated using robust standard errors. ${ }^{\text {a }}$ Control variables included in the models are country of birth, year of study measured as three dummies, gender $\times$ year of study, and the different schools are included as 17 dummies 


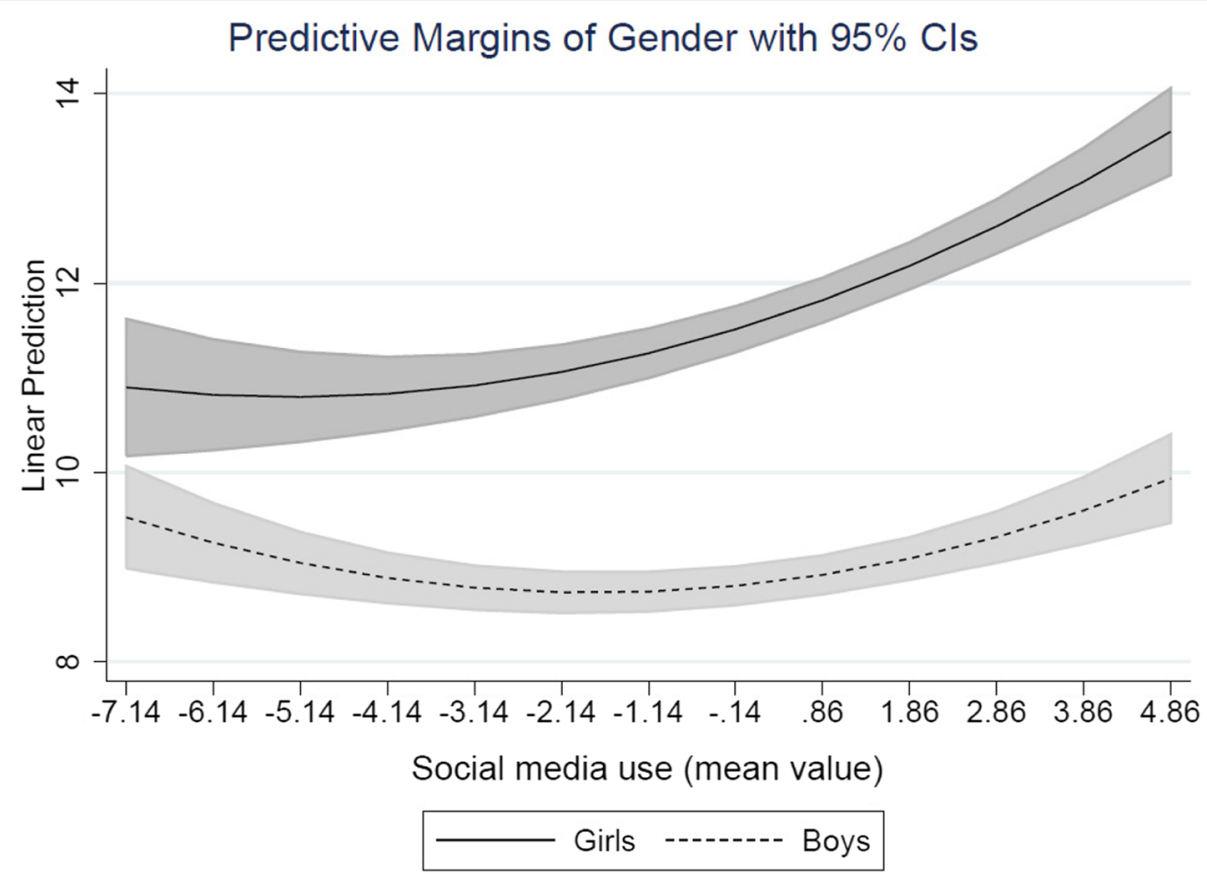

Fig. 1 Interaction between gender and social media use (low value = seldom; high value $=$ often) in the association with predicted values of internalizing symptoms (high value $=$ more symptoms)

online sociability and self-presentation in the association with internalizing symptoms in Table 4. Of the three social media activities, were chatting and self-presentation positively associated with internalizing symptoms, whereas online sociability is negatively associated with internalizing symptoms, adjusting for the other factors presented in model 1. According to the standardized regression coefficients, the results shows that self-presentation is the activity that is most strongly associated with internalizing symptoms of the different digital activities.

Table 4 The relationship between internalizing symptoms and different social media activities and playing games. Ordinary least square regression

\begin{tabular}{|c|c|c|c|c|c|c|}
\hline & \multicolumn{2}{|c|}{ Model 1} & \multirow[b]{2}{*}{$p$-value } & \multicolumn{2}{|l|}{ Model 2} & \multirow[b]{2}{*}{$p$-value } \\
\hline & $B$ & Beta & & $B$ & Beta & \\
\hline Chatting & .300 & .096 & $<.001$ & .287 & .092 & .002 \\
\hline Chatting $^{2}$ & .094 & .049 & .017 & .094 & .050 & .016 \\
\hline Online sociability & -.159 & -.050 & .004 & -.035 & .011 & .696 \\
\hline Self-presentation & .427 & .134 & $<.001$ & .644 & .203 & $<.001$ \\
\hline Playing games & .305 & .091 & $<.001$ & .262 & .079 & .007 \\
\hline Playing games ${ }^{2}$ & .140 & .059 & .001 & .129 & .054 & .006 \\
\hline Boy & -2.339 & -.270 & $<.001$ & -2.309 & -.266 & $<.001$ \\
\hline Chatting $\times$ Boy & & & & .045 & .011 & .656 \\
\hline Online sociability $\times$ Boy & & & & -.215 & -.049 & .057 \\
\hline Self-presentation $\times$ Boy & & & & -.459 & -.100 & $<.001$ \\
\hline Playing games $\times$ Boy & & & & .078 & .014 & .529 \\
\hline Controls ${ }^{a}$ & Yes & & & Yes & & \\
\hline$R^{2}$ & .133 & & & .141 & & \\
\hline $\mathrm{N}$ & 3957 & & & 3957 & & \\
\hline
\end{tabular}

Note: $B=$ unstandardized coefficient; Beta $=$ standardized coefficient. The $p$-values are calculated using robust standard errors. ${ }^{\text {a }}$ Control variables included in the models are country of birth, year of study measured as three dummies, gender $\times$ year of study, and the different schools are included as 17 dummies 
Further, the results in model 2, show that self-presentation interact with gender in the association with internalizing symptoms $(B=-.459, p=<.001)$, indicating that self-presentation is significantly stronger associated with internalizing symptoms for girls than for boys. The results also show that the interaction between gender and online sociability is near significant $(B=-.215, p=.057)$. This interaction indicates that online sociability is negatively associated with internalizing symptoms for boys.

To visualize the interaction between self-presentation and gender, we plotted the predicted values of internalizing symptoms. Figure 2 show that the association between self-presentation and internalizing symptoms is only significant for girls but not for boys.

\section{Discussion}

The current study examined how different digital activities (social media use and playing games), and different types of social media use (chatting, online sociability and self-presentation) are associated with internalizing symptoms as a measure of well-being in adolescent boys and girls. Our primary finding was that social media use was strongly and positively associated with internalizing symptoms in girls. This finding dovetail with previous research highlighting the negative health effects of social media use that offers an arena for self-presentation and self-comparison. Interestingly, the association in our study showed a curvilinear association, suggesting that the association will become stronger as the use of social media increases. The different activities of social media use were differently associated with internalizing symptoms. On the one hand, we found both chatting and self-presentation to be positively associated with internalizing symptoms and demonstrated that self-presentation was more strongly associated with internalizing symptoms for girls. On the other hand, online sociability was negatively associated with internalizing symptoms and this pattern was more pronounced for boys. Finally, our results also indicated that playing games was positively associated with internalizing symptoms.

Our results are consistent with previous cross-sectional [28] and longitudinal [15] studies that found social media use to be more strongly associated with measures of wellbeing for girls than for boys. At the same time, our results contradict findings from other longitudinal studies that found no association between social media use and wellbeing [18-20]. A limitation in some of these longitudinal studies is that they used gender as a control variable and not examined whether the association could be different for boys and girls [20, 22]. Another limitation of previous studies is that varying measures were used to assess social media use. For example, several researchers [22] combined a number of different social media activities within a combined measure of social media use, and others [18] used a measure of social media asking how much

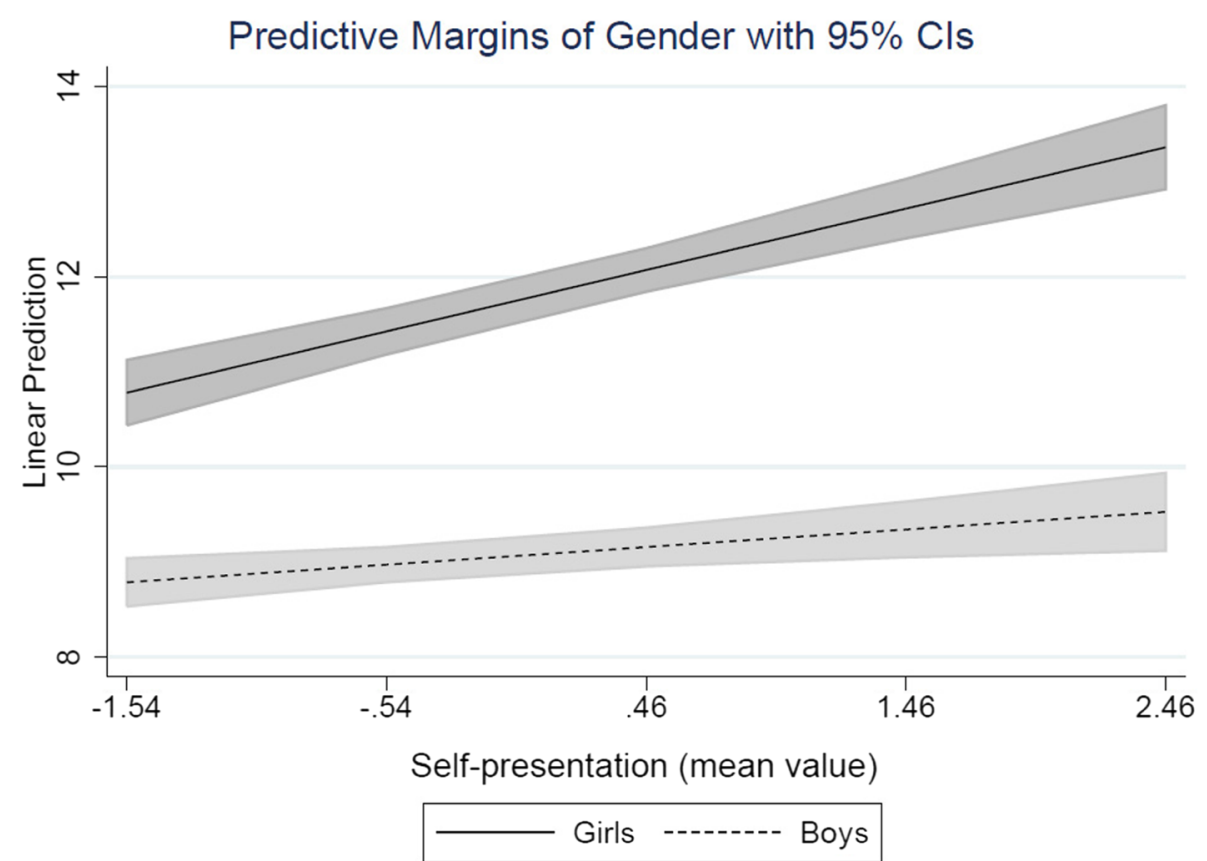

Fig. 2 Interaction between gender and self-presentation (low value=seldom; high value= often) in the association with predicted values of internalizing symptoms (high value = more symptoms) 
time the adolescents spend on social networking (e.g., Facebook) on a typical day.

A key finding in our study is that self-presentation is the social media activity associated with internalizing symptoms for girls. This result is in line with the argument that adolescents that present information about themselves, often in search of likes and followers, will be more susceptible to self-comparisons [35, 39-42], which is known to lead to decrease in well-being [37, 41, 42]. Additionally, not receiving the social rewards one hoped for (e.g., likes and followers), and the presence of social punishers, might be linked to an experienced loss of selfworth, stress and social isolation, all of which are known features of internalizing symptoms [35, 39, 43]. Finally, very few studies have gone beyond establishing an association to trying to explain why there is an association between social media use and well-being [35].

Our study improved on several methodological shortcomings in previous research studying the relationship between social media use and well-being. In particular, we measured (1) both social media use and playing games, (2) different forms of social media use, including chatting, online sociability and self-presentation, which has not been used before in the study of adolescent's well-being, and (3) examined the role of gender.

A few limitations also need to be acknowledged. First, our cross-sectional design constrained our ability to draw any causal conclusions. For example, social media might cause internalizing symptoms, but it is also possible that internalizing symptoms influence social media use and finally, the association can be bi-directional. Our results do, however, closely align with the growing recognition of the role of social media in negatively affecting psychological well-being [35, 41, 42]. A second weakness of our study is that the response options in our survey did not allow for the same resolution in terms of time (number of hours) spent with social media as several previous studies $[1,14]$, although a few previous studies have used similar response alternatives as ours $[15,33]$. This indicates that we cannot determine the exact number of hours that the respondents spend on social medial on a daily basis. That being said, our results nonetheless indicate the importance for future studies to employ more detailed measures of time spend online. Finally, our gaming measure includes both gaming together with other people and gaming alone, making it impossible to draw conclusions about the role of socialization during gaming.

\section{Conclusion}

In conclusion and in line with our hypotheses, our study shows that different social media activities are differently associated with internalizing symptoms as a measure of adolescent's well-being, and that activities entailing self-presentation stand out because of their negative association with well-being for girls, but not boys. Our results suggest that policy makers should be aware of that not all social media activities are created equal in terms of their implications for the health of adolescents, and that these implications might be gender-specific. Future research needs to continue to use increasingly differentiated measures of social media activities, and include both longitudinal and experimental designs to provide a better understanding of how these activities are causally linked to the health of the young.

\section{Acknowledgments \\ Not applicable.}

\section{Authors' contributions}

Design of the study: RS. Data collection: RS, BJ. Conducted statistical analyses: RS. Wrote the first draft of the manuscript: RS. Data interpretation and revisions of the manuscript: RS, BJ, AO. Read and approved the final version of the manuscript: $R S, B J, A O$

\section{Funding}

Open access funding provided by Malmö University. This study was supported by grants from the Public Health Agency of Sweden (02916-2015). Public Health Agency of Sweden supported preparations of the study and data collection for year 2016. The funder was not involved in the design of the study, the data collection, analysis, or interpretation of data or in writing the manuscript.

\section{Availability of data and materials}

The datasets used in the current study are not publicly available due to restrictions made by the Regional Ethical Review Board in Lund, Sweden, but are available from the corresponding author on reasonable request.

\section{Declarations}

\section{Ethics approval and consent to participate}

Informed consent was obtained from all parents and respondents. According to Swedish law on research ethics, parents must give informed consent to research that includes children under the age of 15 . All students were informed about the project both verbally and in writing prior to the initiation of the data collection process. The project has been assessed and approved by the Regional Ethics Review Board in Lund (application no. 2016/88). All methods were carried out in accordance with relevant guidelines and regulations.

\section{Consent for publication}

Not applicable.

\section{Competing interests}

The authors declare that they have no competing interests.

\section{Author details}

${ }^{1}$ Department of Criminology, Malmö University, 20506 Malmö, Sweden. ${ }^{2}$ Department of Social Work, Malmö University, 20506 Malmö, Sweden. ${ }^{3}$ Department of Clinical Neuroscience, Division of Psychology, Karolinska Institutet, 17177 Stockholm, Sweden.

Received: 5 May 2021 Accepted: 28 January 2022

Published online: 10 February 2022

\section{References}

1. Twenge JM, Farley E. Not all screen time is created equal: associations with mental health vary by activity and gender. Soc Psychiatry Psychiatr Epidemiol. 2021;56:297-17 https://doi.org/10.1007/s00127-020-01906-9. 
2. Swedish media council. Ungar \& medier 2021. Report from Swedish media council. 2021.

3. Pew Research Center. 2018. https://www.pewresearch.org/internet/2018/ 05/31/teens-social-mediatechnology-2018/.

4. McManus S, Gunnell D, Cooper C, Bebbington PE, Howard LM, Brugha T. Prevalence of non-suicidal self-harm and service contact in England, 2000-14: repeated cross-sectional surveys of the general population. Lancet Psychiatry. 2019;6:573-81.

5. Mercado MC, Holland K, Leemis RW, Stone DM, Wang J. Trends in emergency departments visits for nonfatal self-inflicted injuries among youth aged 10 to 24 years in the United States, 2001-2015. JAMA. 2017;318:1931-3

6. Thorisdottir IE, Asgeirsdottir BB, Sigurvinsdottir R, Allegrante JP, Sigfusdottir ID. The increase in symptoms of anxiety and depressed mood among Icelandic adolescents: time trend between 2006 and 2016. Eur J Pub Health. 2017:27:856-61.

7. National Board of Health and Welfare. Utvecklingen av psykisk ohälsa bland barn och unga vuxna. Till och med 2016. Report nr: 2017;2017-12-29.

8. McCrae N, Gettings S, Purssell E. Social media and depressive symptoms in childhood and adolescence: a systematic review. Adolesc Res Rev. 2017;2:315-30

9. Twenge JM, Haidt J, Joiner TE, Campbell WK. Underestimating digital media harm. Nat Hum Behav. 2020;4:346-8.

10. Orben A, Przybylski AK. Reply to: underestimating digital media harm. Nat Hum Behav. 2020;4:349-51. https://doi.org/10.1038/s41562-020-0840-y.

11. Stiglic N, Viner RM. Effects of screentime on the health and well-being of children and adolescents: a systematic review of reviews. BMJ Open. 2019;9:e023191.

12. Odgers $C L$, Jensen MR. Annual research review: adolescent mental health in the digital age: facts, fears, and future directions. J Child Psychol Psychiatry. 2020. https://doi.org/10.1111/jcpp.13190.

13. Valkenburg PM, Meier A, Beyens I. Social media use and its impact on adolescent mental health: an umbrella review of the evidence. Curr Opin Psychol. 2021. https://doi.org/10.1016/j.copsyc.2021.08.017.

14. Boers E, Afzali MH, Newton N, Conrod P. Association of Screen Time and Depression in adolescence. JAMA Pediatr. 2019;173:853-9.

15. Viner RM, Gireesh A, Stiglic N, Hudson LD, Goddings A-L, Ward JL, et al. Roles of cyberbullying, sleep, and physical activity in mediating the effects of social media use on mental health and wellbeing among young people in England: a secondary analysis of longitudinal data. Lancet Child Adolesc Health. 2019;3:685-96.

16. Riehm KE, Feder KA, Tormohlen KN et al. Associations between time spent using social media and internalizing and externalizing problems among US youth. JAMA Psychiatry. 2019;76:1266-73.

17. McNamee P, Mendolia S, Yerokhin O. Social media use and emotional and behavioural outcomes in adolescence: evidence from British longitudinal data. Econ Hum Biol. 2021;41:100992.

18. Coyne SM, Rogers AA, Zurcher JD, Stockdale L, Booth M. Does time spent on social media impact mental health?: an eight year longitudinal study. Comput Hum Behav. 2020;104:106160.

19. Beeres DT, Andersson F, Vossen HGM, Galanti MR. Social media and mental health among early adolescents in Sweden: a longitudinal study with 2-year follow-up (KUPOL study). J Adolesc Health. 2021;68:953-60. https://doi.org/10.1016/j.jadohealth.2020.07.042.

20. Orben A, Przybylski AK. Screens, teens, and psychological well-being: Evidence from three time-use-diary studies. Psychol Sci. 2019;30:682-96.

21. Heffer T, Good M, Daly O, MacDonell E, Willoughby T. The longitudinal association between social-media use and depressive symptoms among adolescents and young adults: an empirical reply to Twenge et al. (2018). Clin Psychol Sci. 2019;7:462-70.

22. Puukko K, Hietajärvi L, Maksniemi E, Alho K, Salmela-Aro K. Social media use and depressive symptoms - a longitudinal study from early to late adolescence. Int J Environ Res Public Health. 2020;17:5921. https://doi. org/10.3390/ijerph17165921.

23. Suchert V, Hanewinkel R, Isensee B. Sedentary behavior and indicators of mental health in school-aged children and adolescents: a systematic review. Prev Med. 2015;76:48.57.

24. Wang K, Frison E, Eggermont S, Vandenbosch L. Active public Facebook use and adolescents' feelings of loneliness: evidence for a curvilinear relationship. J Adolesc. 2018;67:35-44.
25. Kaye LK, Orben A, Ellis DA, Hunter SC, Houghton S. The conceptual and methodological mayhem of "screen time". Int J Environ Res Public Health. 2020;17:3661.

26. Twenge JM, Campbell WK. Associations between screen time and lower psychological well-being among children and adolescents: evidence from a population-based study. Prev Med Rep. 2018;12:271-83.

27. Hrafnkelsdottir SM, Brychta RJ, Rognvaldsdottir V, Gestsdottir S, Chen $K Y$, Johannsson E, et al. Less screen time and more frequent vigorous physical activity is associated with lower risk of reporting negative mental health symptoms among Icelandic adolescents. PLoS One. 2018;13:e0196286.

28. Twenge JM, Martin GN. Gender differences in associations between digital media use and psychological well-being: evidence from three large datasets. J Adolesc. 2020;79:91-102.

29. Pappa E, Apergi F-S, Ventouratau R, Janikian M, Beratis IN. Online gaming behavior and psychological well-being in Greek adolescents. Eur I Soc Behav Sci. 2016;60:1988-98.

30. Lobel A, Engels RC, Stone LL, Burk WJ, Granic I. Video gaming and children's psychosocial wellbeing: a longitudinal study. J Youth Adolesc. 2017:46:884-97.

31. Mihara S, Higuchi S. Cross-sectional and longitudinal epidemiological studies of internet gaming disorder: a systematic review of the literature. Psychiatry Clin Neurosci. 2017;71:425-44.

32. Woods HC, Scott H. \#Sleepyteens: social media use in adolescence is associated with poor sleep quality, anxiety, depression and low selfesteem. J Adolesc. 2016;51:41-9.

33. Kreski N, Platt J, Rutherford C, Olfson M, Odgers C, Schulenberg J, et al. Social media use and depressive symptoms among United States adolescents. J Adolesc Health. 2021;68:572-9. https://doi.org/10.1016/j.jadoh ealth.2020.07.006

34. Orben A, Dienlin T, Przybylski AK. Social media's enduring effect on adolescent life satisfaction. Proc Natl Acad Sci. 2019;116:10226-8.

35. Kross E, Verduyn P, Sheppes G, Costello CK, Jonides J, Ybarra O. Social media and well-being: pitfalls, Progress, and next steps. Trends Cogn Sci. 2021;25:55-66. https://doi.org/10.1016/j.tics.2020.10.005.

36. Orben A. Teenagers, screens and social media: a narrative review of reviews and key studies. Soc Psychiatry Psychiatr Epidemiol. 2020;55:407-14.

37. Skogen JC, Hjetland GJ, Bøe T, Hella RT, Knudsen AK. Through the looking glass of social media. Focus on self-presentation and association with mental health and quality of life. A cross-sectional survey-based study. Int J Environ Res Public Health. 2021;18:3319.

38. Subrahmanyam K, Šmahel D. Constructing identity online: identity exploration and self-presentation. In: Digital youth: the role of Media in Development. New York: Springer; 2011. p. 59-80.

39. Nesi J, Prinstein MJ. In search of likes: Iongitudinal associations between adolescents' digital status seeking and health-risk behaviors. J Clin Child Adolsc Psychol. 2019;48:740-8.

40. Verduyn P, Gugushvili N, Massar K, Täht K, Kross E. Social comparison on social networking sites. Curr Opin Psychol. 2020;36:32-7.

41. Yang FR, Wei CF, Tang JH. Effect of Facebook social comparison on wellbeing: a meta-analysis. J Internet Technol. 2019;20:1829-36.

42. Yoon S, Kleinman M, Mertz J, Brannick M. Is social network site usage related to depression? A meta-analysis of Facebook-depression relations. J Affect Disord. 2019;248:65-72. https://doi.org/10.1016/j.jad.2019.01.026.

43. McClean SA, Jarman HK, Rodgers RF. How do "selfies" impact adolescents' well-being and body confidence? A narrative review. Psychol Res Behav Manag. 2019;12:513-21.

44. Rosenthal-von der Pütten AM, Hastall MR, Köcher S, Meske C, Heinrich T, Labrenz F, et al. "Likes" as social rewards: their role in online social comparison and decisions to like other peoples's selfies. Comput Hum Behav. 2019:92:76-86.

45. Blomqvist I, Henje Blom E, Hägglöf B, Hammarström A. Increase of internalized mental health symptoms among adolescents during the last three decades. Eur J Pub Health. 2019;29:925-31.

46. Frison $\mathrm{E}$, Eggermont $\mathrm{S}$. Exploring the relationships between different types of Facebook use, perceived online social support, and adolescents' depressed mood. Soc Sci Comput Rev. 2016;34:153-71.

47. Dhir A, Pallesen S, Torsheim T, Andreassen CS. Do age and gender differences exist in selfie-related behaviours? Comput Hum Behav. 2016;63:549-55. 
48. Gioia F, McLean S, Griffiths MD, Boursier V. Adolescents'selfie-taking and selfie-editing: a revision of the photo manipulation scale and a moderated mediation model. Curr Psychol. 2021:1-17. https://doi.org/10.1007/ s12144-021-01702-x.

49. Booker CL, Kelly YJ, Sacker A. Gender differences in the associations between age trends of social media interaction and well-being among 10-15 year olds in the UK. BMC Public Health. 2018;18:321.

50. Kelly Y, Zilanawala A, Booker C, Sacker A. Social media use and adolescent mental health: findings from the UK Millenium cohort study. EClinicalMedicine. 2018;6:59-68.

51. Johnson B, Svensson R. Alcohol drinking among adolescents with nativeSwedish and non-European immigrant background: the importance of parental attitudes and peer attitudes for acculturation. Drugs Educ Prev Policy. 2021;28:255-66.

52. Svensson $R$, Johnson $B$. Internet use and adolescent drinking: does it matter what young people do online? Drug Alcohol Depend. 2020;213:108138.

53. Svensson R, Johnson B, Kronkvist K. A community intervention to reduce alcohol consumption and drunkenness among adolescents in Sweden: a quasi-experiment. BMC Public Health. 2021;21:1-10.

54. Achenbach TM. The classification of children's psychiatric symptoms: a factor analytic study. Psychol Monogr Gen Appl. 1966:80:1.

55. Goodman R. The strengths and difficulties questionnaire: a research note. J Child Psychol Psychiatry. 1997;38:581-6.

56. Ganzach Y. Misleading interaction and curvilinear terms. Psychol Methods. 1997:3:235-47.

57. Lubinski D, Humphreys LG. Assessing spurious "moderator effects": illustrated substantively with the hypothesized ("synergistic") relation between spatial and mathematical ability. Psychol Bull. 1990;107:385-93.

\section{Publisher's Note}

Springer Nature remains neutral with regard to jurisdictional claims in published maps and institutional affiliations.

- fast, convenient online submission

- thorough peer review by experienced researchers in your field

- rapid publication on acceptance

- support for research data, including large and complex data types

- gold Open Access which fosters wider collaboration and increased citations

- maximum visibility for your research: over 100M website views per year

At BMC, research is always in progress.

Learn more biomedcentral.com/submissions 